\title{
Socio-Spatial Practices: An Introduction and Overview
}

\author{
Therese Kenna $^{1(\bowtie)}$ (D) and Gabriela Maksymiuk ${ }^{2}$ (D) \\ ${ }^{1}$ University College Cork, Cork, Ireland \\ t.kenna@ucc.ie \\ ${ }^{2}$ Warsaw University of Life Sciences, Warsaw, Poland \\ gabriela_maksymiuk@sggw.pl
}

\section{Introduction: Socio-Spatial Practices}

We are now firmly in a digital era and technologies are ever-present. Since the introduction of new digital technologies and ICTs, such as smart phones, the literature has presented some contrasting analyses of the socio-spatial practices and impacts that have resulted from the uptake of new technologies in urban public spaces. On one hand, there is a particular set of debates that have expressed concerns that the introduction of digital technologies, especially personal ICTs, is leading to a greater withdrawal from urban public spaces. For example, the work by Hampton and Gupta (2008) and Hampton et al. (2010) examined uses of ICTs in urban public spaces. They concluded that people who were using technology in public spaces were not actively engaged in the public spaces and were merely "silent spectators". This allowed for a 'public privatism' and created concerns for a widening of the gaps between public and private and a decline of public spaces. These sorts of findings create concerns for the diminishing value of public space in a traditional sense, for the declining significance of public spaces in the digital era, and for the potential of ICTs to generate and increase social inequalities, as well as reduce opportunities for encountering 'others' in the city.

Somewhat contrary to such studies are a number of recent examples of the ways in which social media, smart phones and other platforms are used to encourage physical gathering in public squares, citing examples such as the Arab Springs, anti-austerity protests in Europe, and the Occupy movement that quickly spread globally (Dieter and van Doorn 2013). In these instances, the gatherings in public spaces can be recorded through video and photography and uploaded in real time to the Web, transforming individuals into a collective to address political issues (Dieter and van Doorn 2013). What emerges as apparent then, following Willis (2007, p. 160), is that wireless communication technologies such as smart phones can enable 'multiple social realities' to occur in a single place. While we are witnessing evidence of the potentials for ICTs, like smart phones, to create new social spaces, this is primarily through the use of social media and technologies to create new political functions for citizens and public spaces via gathering and protest.

The contrasting perspectives offer a snapshot of some the ways in which new technologies, especially ICTs, are thought to be transforming the nature of social 
relationships and of socio-spatial practices in urban public spaces. One criticism that has emerged from some of the recent research is directed towards the inadequacies that current social research methods present when researching in the digital era. Digital and online methods are now increasing in popularity, albeit in limited ways. Social networking sites such as Facebook and Twitter are being used to conduct social research and as such are opening up the production of knowledge and new ways of understanding. In particular, online spaces, such as Twitter and Facebook, are being increasingly used as digital data sources for researchers where content analysis of the data, that is publicly available on such sites, is being performed (see Dowling et al. 2015). Latham (2014, p. 111) noted how social media technologies and websites have become a rich source of data, with things like Twitter forming 'micro-diaries' of lived experience. Latham notes, however, that researchers are only beginning to explore the potential of social media technologies to generate electronic diaries of everyday lives. That is, the use of digital spaces and social media platforms for research activities and as data gathering spaces is relatively new. A paper by de Freitas (2010, p. 640) that reviewed current research on the implications of ICTs for the city and everyday social life, noted that the increasing prevalence of digital realities opens up new opportunities for imaginative research techniques such as interviews conducted via social networking sites or real-time archiving of field-notes in 140 characters or less on Twitter, which can be additions to the more established research methods for social sciences researchers. A recent article by De Jong (2014) reflected on the use of one online space, Facebook, as a site for storytelling in research. De Jong's (2014, p. 1) research with festival participants used the online space of Facebook. This research project ultimately concluded that Facebook "has the potential to allow for different ways of knowing that cannot be ascertained in more orthodox research spaces". As De Jong (2014) argued, there is a strong need to re-imagine the ways in which various online spaces may be incorporated as sites for methodologies (p. 2). The Chapters in Part II contribute to these emerging literature and debates by offering novel perspectives on both research methods for analysing the socio-spatial practices in urban public spaces in the digital era, and empirical data into emerging socio-spatial practices and outcomes.

Beyond these two sets of debates, there is emerging research and literature on the ways that ICTs can be used in urban professions, such as urban planning and design. Here, the research to-date is exploring the potential opportunities that might exist when ICTs are used in urban planning, especially for the ways in which ICTs can lead to more user-friendly or people-centred urban spaces, as well as more inclusionary urban planning, design and development processes, that are bottom-up, rather than top-down, and open to diverse socio-spatial practices. ICTs in urban environments deal with several issues, i.e. citizen activism, governance or urban planning. For all these issues, ICTs give a possibility for 'electronic' versions of activities or actions that traditionally had been organised in physical realities. Thus nowadays, we face a specific duality of virtual and physical as, for example, citizen activism can take the form of e-activism, governance can be changed with e-governance and even democracy can be outlined as e-democracy. The case studies and examples showing that new technological solutions increase in general the participation and public engagement in urban issues are numerous, but at the same time there are contrary opinions that omnipresent new technologies can cause the exclusion of some users. The findings of research performed 
by Yeh (2017) on participation with Taiwanese citizens, reveal that they are willing to accept and use the ICT-based smart city services, and that the access to 'e-services' resulted in higher quality of life being achieved. Also, work by Soomro et al. (2017) presenting results from an EU FP7 project called 'urbanAPI', in which 3 different ICT applications addressing diverse aspects of participatory urban governance were tested in four countries, show that the studied applications are useful tools especially for: enhancing spatial planning assessments, activating public participation and 'communicating proposed plans to different stakeholders and identifying key development issues which can provide crucial inputs in planning and decision making processes' (p. 419). On the other hand, according to recent findings of Ertiö and Bhagwatwar (2017) nowadays citizens are more interested and capable to use and benefit from online platforms that facilitate urban planning. Furthermore, Mueller et al. (2018) argues that even though the last decades in urban design research are characterised by a focus on smart cities, actualised through advanced technological aspects of cities, nowadays we are aware that a good infrastructure and sustainable energy supply do not make liveable cities alone, but we also need a citizens' input and feedback. This approach of harnessing information from urban users is greatly enhanced by ICTs and is essential for reaching a responsive city (p. 181). The recent Swedish studies show that the outdoor mobile augmented reality tools facilitate on-site multi-stakeholder urban design and gathering of crowdsourced data, and thus 'mobile and cloud-based computing technologies open up possibilities for multi-stakeholder inclusion in urban planning' (Imottesjo and Kain 2018, p. 1). However, as stated above quite opposite findings are also present. For example, the Finnish study on the appropriation process of two public computing infrastructures in the City of Oulu, a municipal WiFi network and large interactive displays, showed that while the use of the WiFi network has grown steadily, the use of the displays has been declining (Ylipulli et al. 2014). Positioned within these recent debates and the emerging literature, the Chapters in Part II offer some discussions and case study research into the ways new technologies, such as Twitter and participatory GIS, can offer urban planning and design professionals useful tools for understanding social behaviours, attitudes and diverse sociospatial practices, which will ultimately enable more inclusive design, planning and decision-making processes, as well as more inclusionary urban public spaces.

\section{Urban Ethnography}

The chapters in Part II are also the result of the working group on urban ethnography in the CyberParks COST Action TU1306. The aim of this working group was to bring together knowledge about the uses of new technologies in public spaces and to create new understandings of the relationships between public spaces and social behaviour in the digital era, in order to understand how to best connect technology with public spaces for socially sustainable outcomes. The working group was concerned with theoretical and methodological approaches, as well as novel research findings. The leading questions for the working group were: What is known about the relationship between new media use and spatial practices? What do people want from public space? 
Does this differ by socioeconomic status, gender, age? What technological developments are most likely to enhance current user behaviour or develop new user behaviours? Essentially, the improvement, through Information and Communication Technologies (ICT), of the quality of urban life, the inclusion and social participation in the design of public open spaces (POS), and the development of tools for studying and supporting urban planning, were basic goals for the working group.

\section{Overview of Chapters}

The Chapters in this section of the book fall into three broad categories. Firstly, are those concerned with the generation of novel empirical data on the emerging sociospatial practices resulting from the increased uptake of ICTs within urban public spaces. Secondly, are papers that focus on the need for methodological development to be able to capture the new socio-spatial practices in the digital era. Finally, there are two papers that focus on the contributions of ICTs and new technologies to urban professionals.

The first chapter 2.2 by Marluci Menezes, Paschalis Arvanitidis, Therese Kenna and Petja Ivanova-Radovanova is entitled 'People-space-technology: an ethnographic approach'. This chapter is concerned with ethnographic research methodologies in the digital era. In particular, this chapter questions the utility of current ethnographic approaches and develops a new framework to guide researchers undertaking research relating to peoples use of technology in urban space. The authors argue that in the digital era, ethnographic research is required to capture, explore and understand the cyber-social phenomena and dynamics in a multifaceted, hybrid, triangulated and cross-referenced way, which makes the research more complex and perhaps more stimulating. By providing an integrated framework for the analysis of the relationships between people, space and technology, the authors of this Chapter argue that the ethnographic approach is enriched, as is our knowledge of socio-spatial practices in urban public spaces.

Following this, in chapter 2.3 Paschalis Arvanitidis, Therese Kenna, and Gabriela Maksymiuk explore university students use of ICTs in university public spaces, entitled "Public space engagement and ICT usage by university students: an exploratory study in three countries". The research in these locations examined how university students perceive and use the public spaces on their university campuses, and how they now use personal technologies, such as smart phones, within these spaces. Importantly, the research in this Chapter is based on data that was collected from an online questionnaire, and thus new digital methods were used in this study. The research is conducted in three geographic locations: University College Cork in Cork (Ireland), the University of Thessaly in Volos (Greece), and the Warsaw University of Life Sciences in Warsaw (Poland), which has allowed for novel insights into the differences and similarities that arise in these differing contexts.

The work presented by Marluci Menezes, Paschalis Arvanitidis, Carlos Smaniotto Costa and Zvi Weinstein entitled 'Teenagers' perception of public spaces and their ICTs practices' (chapter 2.4) focusses on a cohort of the population who are deemed to be tech-savvy and thus heavily intertwined in the debates about the 
new socio-spatial practices in urban public spaces in the digital era. In this chapter, the authors shed light on the perceptions and practices of adolescents, as obtained via structured interviews with teenagers living in Hannover (Germany), Lisbon (Portugal), Tel Aviv (Israel) and Volos (Greece). The study is small-scale and offers some preliminary results that are argued to be indicative of possible wider trends and attitudes. In particular, the authors articulate how young people from distinct sociocultural contexts perceive and use both public spaces and digital technologies, and thus they identify teenagers emerging socio-spatial practices.

The chapter 2.5 by Montserrat Pallares-Barbera, Elena Masala, Jugoslav Jokovic, Aleksandra Djukic and Xavier Albacete is entitled "Challenging methods and results obtained from user-generated content in Barcelona's urban open spaces". This chapter examines user-generated content from Twitter users in Barcelona, Spain. The research examined the spatial signatures that result from the twitter uses in different public open spaces in Barcelona. It is argued that the analysis of the data offers insights into new social behaviours that are emerging in public spaces and of a range of multifunctional uses within the public spaces. The authors argue that usergenerated content (UGC) provides useful resources for academics, technicians and policymakers to obtain and analyse results in order to improve lives of individuals in urban settings. They argue, similar to the emerging debates in the literature noted in the introduction, that there are new methodologies and new data sources, such as Twitter, that can offer new insights into socio-spatial practices in urban public spaces and thus these new insights can better inform urban planning practice.

The final chapter 2.6 in Part II by Antoine Zammit, Therese Kenna and Gabriela Maksymiuk, entitled "Social implications of new mediated spaces: the need for a rethought design approach", examines the ways in which ICTs can be utilised as tools for enhancing urban planning and design process for more inclusionary urban public spaces. In this Chapter, case studies are presented from three European urban contexts - the UK, Poland and Malta - where research has been conducted into the use of participatory digital mapping for citizen participation in urban planning and design. Here, ICT tools such as PGIS, or SoftGIS, are discussed for their abilities to engage a wider range of social groups in planning and design processes than might be obtained through more traditional methods of participation, such as written submissions or faceto-face meetings. Ultimately, new technologies have allowed for an expansion of the tools and methods available for participation in urban planning and design processes, thus allowing urban professionals to have access to a greater range of socio-spatial practices and behaviours. This will essentially allow for the design of more inclusive urban public spaces, designed with a diverse range of social groups and users in mind.

Each of the chapters in Part II offer new contributions to knowledge relating to the use of digital technologies in urban public spaces, the methodologies for understanding the new relationships and practices, and the applications of new technologies in the design of urban public spaces. Chapters 2.2 and 2.5 present strong arguments for the need for new research methods to analyse the people-space-technology triad. Chapters $2.3,2.5$ and 2.6 offer examples of the ways in which digital methods can be used to analyse new socio-spatial practices and attitudes in urban public spaces. Beyond the methodological contributions, the work in Chapters 2.3, 2.4 and 2.5 all offer new insights into the lived experiences of new technologies in urban public spaces, albeit 
through small-scale pilot studies and preliminary analyses. Importantly, the work in Chapters 2.3 and 2.4 has strongly argued for the need to develop research that spans different social and cultural contexts, as this enables us to reveal the differences and similarities that can occur in the uses, perceptions and relationships between technology, people and urban space. Further, the work in chapters 2.5 and 2.6 highlight the ways that new technologies can be harnessed for urban design and planning, by using tools such as Twitter and PGIS to understanding a wider range of socio-spatial practices than traditional methods might allow, and ultimately allow for a more inclusive planning and design process and outcome. In all, the chapters in Part II contribute to emerging debates in the literature.

\section{References}

Ertiö, T.-P., Bhagwatwar, A.: Citizens as planners: harnessing information and values from the bottom-up. Int. J. Inf. Manage. 37(3), 111-113 (2017)

De Freitas, A.: Changing spaces: locating public space at the intersection of the physical and digital. Geogr. Compass 4(6), 630-643 (2010)

De Jong, A.: Using Facebook as a space for storytelling in geographical research. Geogr. Res. 53 (2), 211-223 (2014)

Dieter, M., van Doorn, N.: Urban Social Spaces: Tactical Media in the Hybrid City’. New Media Theories - Research Essay (2013)

Dowling, R., Lloyd, K., Suchet-Pearson, S.: Qualitative methods 1: enriching the interview. Prog. Hum. Geogr. 40, 1-8 (2015)

Hampton, K.N., Gupta, N.: Community and social interaction in the wireless city: Wi-Fi use in public and semi-public spaces. New Media Soc. 10(6), 831-850 (2008)

Hampton, K., Livio, O., Sessions Goulet, L.: The social life of wireless urban spaces: internet use, social networks, and the public realm. J. Commun. 60, 701-722 (2010)

Imottesjo, H., Kain, J.H.: The urban cobuilder - a mobile augmented reality tool for crowdsourced simulation of emergent urban development patterns: requirements, prototyping and assessment. In: Computers, Environment and Urban Systems (2018). https://doi.org/10.1016/ j.compenvurbsys.2018.05.003

Latham, A.: Using diaries to study urban worlds'. In: Ward, K. (ed.) Researching the City: A Guide for Students. Sage, London (2014)

Mueller, J., Lu, H., Chirkin, A., Klein, B., Schmitt, G.: Citizen design science: a strategy for crowd-creative urban design. Cities 72(Part A), 181-188 (2018)

Soomro, K., Khan, Z., Ludlow, D.: Participatory governance in smart cities: the urban API case study. Int. J. Serv. Technol. Manage. 23(5/6), 419-444 (2017)

Willis, K.: Sensing place - mobile and wireless technologies in urban space. In: Meier, L., Frers, L. (eds.) Encountering Urban Places: Visual and Material Performances in the City. Ashgate, Aldershot (2007)

Yeh, H.: The effects of successful ICT-based smart city services: from citizens' perspectives'. Gov. Inf. Q. 34(3), 556-565 (2017)

Ylipulli, J., Suopajärvi, T., Ojala, T., Kostakos, V., Kukka, H.: Municipal WiFi and interactive displays: appropriation of new technologies in public urban spaces. Technol. Forecast. Soc. Chang. 89, 145-160 (2014). https://doi.org/10.1016/j.techfore.2013.08.037 
Open Access This chapter is licensed under the terms of the Creative Commons Attribution 4.0 International License (http://creativecommons.org/licenses/by/4.0/), which permits use, sharing, adaptation, distribution and reproduction in any medium or format, as long as you give appropriate credit to the original author(s) and the source, provide a link to the Creative Commons license and indicate if changes were made.

The images or other third party material in this chapter are included in the chapter's Creative Commons license, unless indicated otherwise in a credit line to the material. If material is not included in the chapter's Creative Commons license and your intended use is not permitted by statutory regulation or exceeds the permitted use, you will need to obtain permission directly from the copyright holder. 